\title{
The Role of Bystanders in the Prevention of Railway Suicides in New South Wales, Australia
}

\author{
Nguyen Viet Ngo', Shirley D. Gregor'®, Gary Beavan², and Bianca Riley² \\ ${ }^{1}$ Research School of Management, Australian National University, Canberra, ACT, Australia \\ ${ }^{2}$ Transport for NSW, Haymarket, Sydney, NSW, Australia
}

\begin{abstract}
Background: Bystanders can play a key role in preventing railway suicides by taking direct action or by raising an alarm. Aims: The study investigated in this context: (1) the prevalence of preventative actions by bystanders; (2) the relationship, if any, between first-hand preventions by bystanders and the degree of ambiguity around the imminence of danger; and (3) the nature of first-hand preventions by bystanders. Method: Data were obtained from a security reporting database at Sydney Trains for 2011-2019 for accident and suicide-related incidents $(N=1,278)$. Results: In 635 cases of suicide prevention, bystanders were identified as first responders in $11 \%$ of cases and as raising the alarm in $11 \%$ of cases. Bystanders as first responders intervened proportionally more where the ambiguity of danger is low (jumping) compared with high (sitting, standing, wandering). Of the 69 cases of bystander preventions, $77 \%$ involved physical interaction (e.g., holding back) and $49 \%$ involved more than one bystander. Limitations: The data source could be biased because of incompleteness or nonstandard reporting. Conclusion: Rail policy-makers should consider education and support for bystanders and staff: for example, by making known the prevalence of helping, the importance of intervening, and what types of intervention are most helpful.
\end{abstract}

Keywords: railway, suicide, prevention, bystanders, first responders

The problem of railway suicides and attempted suicides is an important one. Apart from the personal impact on the individuals involved, there are significant consequences for railway staff, eyewitnesses, other passengers, and rail network operators. Bystanders can play a key role in cases of suspected suicide attempts on railway networks. Such cases can occur at times or locations where bystanders are the only individuals who are able to react by taking direct action themselves or by raising the alarm so others can intervene. The downside of bystander interventions is the person intervening may place themselves at risk of injury and suffer subsequent trauma (Liebst et al., 2018).

Direct interventions by bystanders are defined as actions that bystanders take first-hand to prevent a suicide attempt (Berkowitz, 2009). Examples in the railway context include actions such as entering the track to physically remove a person from the path of a train, stopping a person from jumping from the platform into the path of an oncoming train, or engaging in a conversation with an individual perceived as at risk. These actions are in contrast to indirect intervention, in which bystanders intervene by contacting emergency services or relevant authorities. While there have been field studies into bystander interventions in contexts including crime (Huston et al., 1981), medical emergencies (Faul et al., 2016), surf lifesaving (Attard et al., 2015), and suicide in a public setting (Owens et al., 2019), there have been few dealing with such interventions in the context of railway networks.

Even when a suicide attempt is suspected, there is a chance that bystanders will not react until it is too late, or will not react at all. The bystander effect has been posited - a reluctance of individuals to offer help to someone at risk when other people are present. It is thought that the greater the number of bystanders, the less likely one of them will help in a critical situation (Darley \& Latane, 1968). Latane and Darley (1970) proposed a five-stage model of bystander intervention: noticing; interpreting as an emergency; developing a feeling of personal responsibility; a belief that one has the skills to help; and reaching a conscious decision to help. Other research has found bystanders may be more likely to engage in helping behaviors if they are confronted with dangerous emergencies, where the bystander effect may be attenuated. Three explanations of this phenomenon are advanced by Fischer et al. (2011). First, dangerous situations are more likely to be construed as having low situational ambiguity, which increases experience arousal, and thus helping responses. Second, in these cases, other bystanders can be seen as 
providers of physical support, and thus reduce fear of intervention by one individual. Third, some dangerous emergencies can only be effectively resolved by cooperation and coordination among several bystanders. A large recent study using closed-circuit television (CCTV) footage of reallife bystander intervention in public contexts showed that in 9 out of 10 cases at least one bystander, and typically several, would intervene to help (Philpot et al., 2019).

Prevention of railway suicides is often considered in terms of the behavior by the individual at risk immediately prior to an incident. The nature and opportunity for successful interventions can depend on the nature of this precrash behavior. Dinkel et al. (2011) distinguished three broad groupings of pre-crash behavior: jumping, lying, and wandering. Passive measures such as physical barriers and fencing have been shown to reduce the relative incidence of lying and wandering attempts compared with jumping incidents (Gregor et al., 2019). Active interventions may be fewer in cases of jumping, where an individual makes an attempt by jumping or leaping into the path of a train, compared with cases where an individual is stationary or wandering on tracks for a period, allowing more time for an intervention. On the other hand, an attempt at selfharm by jumping into the path of a train has less situational ambiguity and the imminence of danger is more evident to observers.

The sparseness of research in the area of bystander interventions to prevent suicides on railway networks indicates further work is required. Thus, the aims of the current study were to investigate in the context of railway suicide attempts: (1) the prevalence of preventative actions by bystanders; (2) the relationship, if any, between active, first-hand preventions by bystanders and the degree of ambiguity around the imminence of danger; and (3) the nature of first-hand preventions by bystanders. In terms of an integrated systems approach to suicide prevention (Black Dog Institute, 2019), the study contributes by informing potential strategies for gatekeeper training, reducing access to means, and community awareness programs.

\section{Method}

Our research setting was two heavy rail networks in the state of New South Wales (NSW) in Australia: the Sydney metropolitan network and the regional NSW network. Sydney Trains safety reports show a number of initiatives that can be classified as suicide reduction interventions (e.g., Sydney Trains, 2018). Sydney Trains' policy regarding responsible media reporting of suicides and attempted suicides has been practiced over the whole of the study period. Fencing has been demonstrated to have a significant effect on preventing railway suicide, comparing the relatively well-fenced Sydney metropolitan network with regional NSW's relatively unfenced network (Gregor et al., 2019). The Security Control Centre, acting across NSW, coordinates communication and responses by station staff, police, ambulance, and other stakeholders in cases of emergency, in accordance with standard operating procedures and using mobile communication and CCTV.

The primary data source was a security reporting database maintained for the years 2011-2019 for incidents across the whole NSW rail network. The database is maintained for internal operational purposes by Sydney Trains Security in NSW (see Beavan, 2016). Data are entered during and after each incident by response operators. Fields are maintained for time, day of week, month, year, location, region, and outcome, among others. Outcomes are distinguished as apparent suicide, attempted suicide, death by apparent misadventure, and death (suspicious/undetermined). There is a textual freeform incident summary of 4,192 characters from which further data fields were obtained, where possible, for attempted suicides, including gender, pre-crash behaviors, and relevant variables regarding characteristics of the situation (location, availability of staff, train movement, access points, interveners, etc.). Coding was done manually. For details on the coding, see Electronic Supplementary Material 1 (ESM 1). Due to the nature of the data, nonparametric statistical tests were used ( $\chi^{2}$ tests). A significance value of $p<.05$ was used, unless otherwise noted.

\section{Results}

There has been some degree of success in combatting rail suicide in NSW. The incidence of train suicides remained relatively constant over the period 2011-2019, with an average of 0.28 cases annually per 100,000 head of population in NSW. The incidence of suicides overall in NSW increased significantly from 8.5 in 2011 to 11.22 in 2018 per 100,000 (Australian Bureau of Statistics, 2019a, $2019 b)$. The relatively low rate of rail suicide is in part attributed to the high level and standard of fencing in the Sydney metropolitan area, which deters some attempts (Gregor et al., 2019).

Other factors, however, also play a part. The Sydney Trains database shows there was a high incidence of "prevented suicides," where there was clear evidence that an individual was attempting to come in contact with a train for the purpose of self-harm but was prevented from 
injury or death by the actions of others. Although the rate of rail suicide has remained relatively constant, the rate of attempted suicides has increased markedly, even with the high level of fencing. For the period 2011-2019, the database contained 1,278 cases in total, including cases of misadventure (accident). Of these cases, 984 cases were classed as "attempted suicide" (including non-train attempts). There were 635 cases of attempts at suicide by train that were prevented. There were also 106 injuries and 191 deaths by suicide involving trains.

For the current study, our interest was in the actors who take a role in the active prevention of train suicides (635 cases). Figure 1 shows the frequency of those who were involved in preventions, in terms of "first responders" to an attempt; namely, bystanders, rail personnel at stations, other rail personnel, emergency services, and other/ unknown.

The incidence of bystanders known to be first responders is reasonably high, at 69 of the 635 cases (11\%). Bystanders also raised the alarm and reported, but were not first responders, in another 70 cases. Thus, the total number of cases where bystanders either were first responders or raised the alarm is $139,22 \%$ of the 635 preventions. If bystanders had not played a role in suicide preventions, the number of deaths by suicide could have been 139 cases (73\%) higher than the actual number of 191 .

The literature on bystanders' roles in helping others suggests that bystanders are more likely to provide aid when there is less ambiguity around the danger that the individual at risk faces. In the rail suicide context, the situation in which there is likely to be less ambiguity is when an individual jumps from a platform into the path of a train. The incidents in our database allowed us to distinguish between three categories for pre-crash behavior:
(1) jumping; (2) lying, sitting, or standing on tracks; and (3) wandering or running on tracks. In subsequent analysis we distinguish between the first category of jumping, and "non-jumping" (the other two categories combined), and consider the jumping category as being more unambiguously dangerous. It is expected that bystander preventions as first responders will occur comparatively more often for cases in the jumping category.

Table 1 shows results for the first-responder categories in the cases of prevention. The proportion of prevented jumping cases for the bystander category $(36 \%)$ is higher than in other categories (excluding the unknown/other category). The next highest is for rail personnel on stations (26\%). Analysis of cases where the responder and precrash category could be determined (the bolded figures) shows there is a significant difference among the four main responder categories, in terms of the proportion of preventions for jumping versus non-jumping cases, $\chi^{2}(3$, $N=384)=26.1, p<.001$.

There may be factors other than lack of ambiguity that influence the readiness of bystanders to intervene. It may be also because they are more ready-to-hand, or in fact that they are the only people close by, but it does indicate their willingness to step up when "danger is imminent." Table E3 in ESM 1 summarizes the differences between bystander preventions and other preventions on a range of factors that could be ascertained from the database and could have some bearing on a bystander's preparedness to take action, with results of tests of significance. Comparable figures for deaths by suicide are also presented as a point of reference. Analyses are shown separately for metropolitan Sydney and regional NSW because of the differences between these regions in terms of pre-crash behavior reported by Gregor et al. (2019).

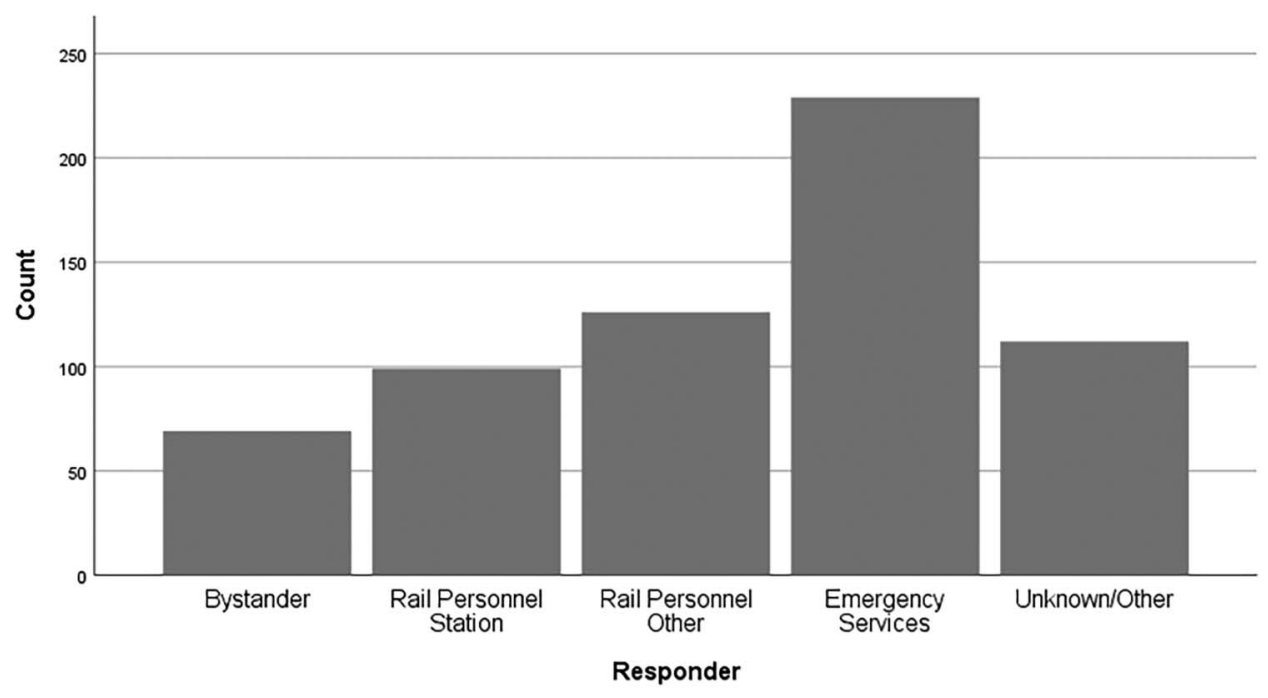

Figure 1. Frequencies for active preventions by first-responder category $(n=635)$. 
Table 1. Analysis of pre-crash behavior vs. first-responder category

\begin{tabular}{|c|c|c|c|c|c|c|}
\hline \multirow[b]{2}{*}{ Pre-crash category } & \multicolumn{5}{|c|}{ Responder category } & \multirow[b]{2}{*}{ Total } \\
\hline & Bystander & Rail personnel station & Rail personnel other & Emergency services & Other & \\
\hline Jumping & 19 & 21 & 15 & 12 & 29 & 96 \\
\hline Non-jumping & 34 & 60 & 86 & 137 & 55 & 372 \\
\hline Other & 16 & 18 & 25 & 80 & 28 & 167 \\
\hline Total & 69 & 99 & 126 & 229 & 112 & 635 \\
\hline
\end{tabular}

Note. Bolded numbers were analyzed with chi-square, showing a significant pattern.

This analysis shows the only significant differences between bystander and non-bystanders are for pre-crash behavior and location (see Table 2). These two factors are related, since nearly all prevented jumping incidents occur at platforms or tracks between platforms $(90.6 \%)$, while prevented non-jumping incidents occur at a lower percentage at platforms $(59.4 \%)$ and more incidents on tracks between stations. No significant differences were found for gender. That is, bystanders were not more likely to prevent attempts by females than by males, or the reverse. This situation differs from cases of death by suicide in our study, where males are more likely than females to die by suicide. This imbalance has been observed elsewhere (Freeman et al., 2017).

The 69 cases of bystander preventions were analyzed in further detail to provide insights into how they were enacted. Table 3 provides excerpts from the database showing how bystanders acted in different circumstances, when the person at risk made a jumping attempt, when they were non-jumping, at a station or not, and the different types of actions that took place. Case 1 shows an example where the person had been wandering about for a period but action was only taken when he attempted to jump, supporting the idea that a bystander is more likely to intervene when the situation is less ambiguously dangerous.

A number of the cases, as Table 3 illustrates, involved physical interaction between the responders and the person at risk. In fact, physical interaction occurred in $85 \%$ of the 69 active prevention cases. Minimal or light interaction, such as blocking or guiding, occurred in $9 \%$ of these cases. Heavier interactions, such as tackling, pulling, holding, grabbing, or restraining, occurred in $77 \%$. In $48 \%$ of these cases, the bystander acted alone, at least in the first instance, and in $49 \%$ of cases more than one bystander acted together (the number was unclear in $3 \%$ ).

\section{Discussion}

The study's first research theme concerns the extent to which bystanders assisted in the prevention of rail suicides. The incidence of bystanders as first responders who actively prevented suicides was $11 \%$ (69 of 635 ). Close to $22 \%$ of all preventions in the NSW railway network in the period 2011-2019 had identified bystander involvement, including bystanders as either reporters of incidents or as first responders (139 of 635). This figure compares favorably with one of the few comparable studies to be found, where data from the United Kingdom suggest that approximately 1 in 10 interventions of all types - direct and indirect - on the railway are by the public (Samaritans, 2018).

The second theme concerns the relationship between bystander interventions and situational ambiguity. There was a significant difference for the situations in which bystanders

Table 2. Comparison of bystander active preventions, other active preventions, and deaths by suicide

\begin{tabular}{|c|c|c|c|c|}
\hline Factor & $\begin{array}{l}\text { Bystander preventions, } n(\%) \\
\qquad(N=69)\end{array}$ & $\begin{array}{l}\text { Other preventions, } n(\%) \\
\qquad(N=566)\end{array}$ & $\chi^{2}$ & $\begin{array}{c}\text { Deaths by suicide, } n(\%) \\
\text { ( } N=191)\end{array}$ \\
\hline Pre-crash behavior & & & $<.001$ & \\
\hline Jumping & $19(35.8 \%)$ & $48(14.5 \%)$ & & $77(57.0 \%)$ \\
\hline Non-jumping & $34(64.2 \%)$ & $283(85.5 \%)$ & & $58(43.0 \%)$ \\
\hline Total known values & $53(100 \%)$ & 331 (100\%) & & $135(100 \%)$ \\
\hline Location (Sydney metro region) & & & $<.001$ & \\
\hline Platform & $15(29.4 \%)$ & $45 \quad(12.1 \%)$ & & $14 \quad(9.5 \%)$ \\
\hline Track near platform & $26(51.0 \%)$ & $191(51.3 \%)$ & & $85(57.4 \%)$ \\
\hline Track not at platform & $4 \quad(7.8 \%)$ & $108(29.0 \%)$ & & $37(25.0 \%)$ \\
\hline Other (e.g., level crossing) & $6(11.8 \%)$ & $28 \quad(7.5 \%)$ & & $12 \quad(8.1 \%)$ \\
\hline Total known values & 51 (100\%) & 372 (100\%) & & $148(100 \%)$ \\
\hline
\end{tabular}


Table 3. Examples showing details of active preventions by bystanders $(n=69)$

\begin{tabular}{|c|c|}
\hline Case & Brief description (anonymized, with explanatory detail in plain text added) \\
\hline \multicolumn{2}{|c|}{ "Jumping" attempts on or near platforms (16 cases) } \\
\hline 1 & $\begin{array}{l}\text { Platform staff called and advised that there had been a POI who had attempted } \\
\text { to jump in front of a service on platform } 3 \text { in the morning but was held back by } \\
\text { another person. The POI then had a brief conversation with the other person. The } \\
\text { POI then said he was on his way to another city to meet his relative... Station staff } \\
\text { further advised that the POI had been walking near the edge of the platforms for } \\
\text { approximately } 1.5 \text { h } \\
\text { Time: } 9 \text { a.m.-midday, Sunday, Suburban Station, Sydney Trains }\end{array}$ \\
\hline \multicolumn{2}{|c|}{ "Sitting" attempts at tracks on or near platforms (7 cases) } \\
\hline 2 & $\begin{array}{l}\text { Police radio called SCC to advise that } 000 \text { has received a phone call from MOP that } \\
\text { at X RWS (railway station) a person is sitting on the train tracks. That a train } \\
\text { sounded its horn. } \\
\text { Conferenced with Ops Outer. SCC live monitor CCTV cam. Ops Outer advise blocks } \\
\text { on. Person on platform drags POI up from track area on to platform. Police } \\
\text { observed to approach. } \\
\text { Police observed to restrain female on platform clear from running line area. } \\
\text { Time: } 9 \text { p.m.-midnight, Thursday, Suburban Station, Sydney Trains }\end{array}$ \\
\hline \multicolumn{2}{|c|}{ "Standing" attempts at tracks near platforms (5 cases) } \\
\hline 3 & $\begin{array}{l}\text { The guard of a train currently on platform, down suburban at Y has come to a stop } \\
\text { due to a person standing in the four foot in front of the service. Guard has advised } \\
\text { he is unable to see the person and the driver is on the radio to the box. Ops advised } \\
\text { SCC of the same. Police called to attend as a matter of urgency. SCC call staff who } \\
\text { advised person has been convinced to come onto platform and is in the company } \\
\text { of } 2 \text { other people who are not allowing the POI to leave. } \\
\text { Time: } 6 \text { p.m.-9 p.m., Friday, Suburban Station, Sydney Trains }\end{array}$ \\
\hline
\end{tabular}

Note. $\mathrm{MOP}=$ member of the public. $\mathrm{POI}=$ person of interest. $\mathrm{SCC}=$ security control center.

responded in terms of pre-crash behaviors - jumping versus non-jumping. Known jumping incidents were approximately $15.1 \%$ of the total of 635 prevented incidents. Bystanders contributed more than would be expected in this category, as $27.5 \%$ of the 69 bystander preventions were known jumping incidents, compared with $13.6 \%$ known jumping incidents of 566 preventions by other parties. This finding is congruent with other work showing that bystanders were more likely to help in situations where there was low ambiguity about the risk of danger (e.g., Fischer et al., 2011). Interpretation of this finding in terms of the classic bystander intervention model of Latane and Darley (1970) suggests that for jumping cases, the stages of noticing, interpreting, and knowing what to do may be more readily accomplished. For more ambiguous cases, such as wandering, education could assist bystanders in noticing, interpreting, and knowing how to help.

The study's third theme concerns the nature of bystander preventions. No significant differences were found between bystander and non-bystander preventions in terms of the gender of the person at risk or the time of day. Bystander preventions were proportionally more likely to occur at or near platforms, compared with open tracks, which is not surprising as bystanders are more likely to be present at platforms. A surprising proportion of the incidents in which bystanders intervened shows a high degree of physicality in interactions, with bystanders tackling, grabbing, or holding the person at risk. In almost half the cases of bystander preventions, there was more than one bystander involved.

\section{Limitations}

The study has certain limitations. Some factors of potential interest, including intoxication, age, ethnicity, occupation, and economic status, are not routinely reported. The values of some factors could not be determined for all cases and had to be treated as unknown. Further, it is not always possible to distinguish cases of apparent suicide attempts from those where other forms of self-harm are intended.

\section{Conclusion}

The railway literature has largely overlooked the role and effectiveness of the public as first responders and reporters in ensuring a safe railway system. Our study shows that over the period of 2011-2019, the number of deaths by suicide could have been up to $73 \%$ higher without 
bystander interventions. Theoretically, our study provides support for Fischer et al. (2011) findings regarding bystander intervention in a clear-cut emergency, where a bystander is more likely to intervene when there is less ambiguity around the risk of danger.

The study also has important practical implications. Efforts to ensure data collected in organizations are as complete and accurate as possible are recommended, across jurisdictions, so that further studies can be undertaken. Here and more generally, the relatively large number of incidents of bystander preventions has implication for policy in public educational campaigns and support for those brave bystanders who risk their own safety. The known interventions by rail staff at $16 \%$ is not much higher than the known interventions by bystanders at $11 \%$. Rail operators should continue their efforts to educate staff in recognizing potential danger and knowing how to help. Further, there are a proportion of cases of deaths by suicide that occur away from platforms $(n=50,26 \%)$, where bystanders and staff are less likely to be able to help. Further work on the efficacy of signage such as Lifeline billboards and preventative barriers is suggested.

\section{Electronic Supplementary Material}

The electronic supplementary material is available with the online version of the article at https://doi.org/ 10.1027/0227-5910/a000804

ESM 1. Coding guide and results details

\section{References}

Attard, A., Brander, R. W., \& Shaw, W. S. (2015). Rescues conducted by surfers on Australian beaches. Accident Analysis \& Prevention, 82, 70-78. https://doi.org/https://doi.org/10.1016/j.aap.2015.05.017

Australian Bureau of Statistics. (2019a). Causes of death, Australia, 2009-2018. https://www.abs.gov.au/statistics/health/causesdeath/causes-death-australia/latest-release

Australian Bureau of Statistics. (2019b). National, state and territory population. https://www.abs.gov.au/statistics/people/ population/national-state-and-territory-population/dec2019\#data-download

Beavan, G. (2016). Fatality intelligence assessment. Sydney Trains (Internal Report).

Berkowitz, A. D. (2009). Response ability: A complete guide to bystander intervention. Beck \& Company.

Black Dog Institute. (2019). Guidance for a systems approach to suicide prevention for rural and remote communities in Australia.

Darley, J. M., \& Latane, B. (1968). Bystander intervention in emergencies: Diffusion of responsibility. Journal of Personality and Social Psychology, 8(4), 377-383. https://doi.org/10.1037/ h0025589

Dinkel, A., Baumert, J., Erazo, N., \& Ladwig, K.-H. (2011). Jumping, lying, wandering: Analysis of suicidal behaviour patterns in 1,004 suicidal acts on the German railway net. Journal of Psychiatric Research, 45(1), 121-125. https://doi.org/10.1016/j.jpsychires.2010.05.005

Faul, M., Aikman, S. N., \& Sasser, S. M. (2016). Bystander intervention prior to the arrival of emergency medical services: Comparing assistance across types of medical emergencies. Prehospital Emergency Care, 20(3), 317-323. https://doi.org/10. 3109/10903127.2015.1088605

Fischer, P., Krueger, J. I., Greitemeyer, T., Vogrincic, C., Kastenmüller, A., Frey, D., Heene, M., Wicher, M., Kainbacher, M., \& Kainbacher, M. (2011). The bystander-effect: A meta-analytic review on bystander intervention in dangerous and non-dangerous emergencies. Psychological Bulletin, 137(4), 517-537. https://doi.org/10. 1037/a0023304

Freeman, A., Mergl, R., Kohls, E., Székely, A., Gusmao, R., Arensman, E., Koburger, N., Hegerl, U., \& Rummel-Kluge, C. (2017). A cross-national study on gender differences in suicide intent. BMC Psychiatry, 17(1), 234. https://doi.org/10.1186/s12888-017-1398-8

Gregor, S., Beavan, G., Culbert, A., Kan John, P., Ngo, N. V., Keating, B., Sun, R., \& Radwan, I. (2019). Patterns of pre-crash behaviour in railway suicides and the effect of corridor fencing: A natural experiment in New South Wales. International Journal of Injury Control and Safety Promotion, 26(4), 423-430. https://doi.org/ 10.1080/17457300.2019.1660376

Huston, T. L., Ruggiero, M., Conner, R., \& Geis, G. (1981). Bystander intervention into crime: A study based on naturally-occurring episodes. Social Psychology Quarterly, 44(1), 14-23. https://doi. org/10.2307/3033858

Latane, B., \& Darley, J. M. (1970). The unresponsive bystander: Why doesn't he help? Prentice Hall.

Liebst, L. S., Heinskou, M. B., \& Ejbye-Ernst, P. (2018). On the actual risk of bystander intervention. Journal of Research in Crime and Delinquency, 55(1), 27-50. https://doi.org/10.1177/ 0022427817710776

Owens, C., Derges, J., \& Abraham, C. (2019). Intervening to prevent a suicide in a public place: A qualitative study of effective interventions by lay people. BMJ Open, 9(11), e032319. https://doi. org/10.1136/bmjopen-2019-032319

Philpot, R., Liebst, L. S., Levine, M., Bernasco, W., \& Lindegaard, M. R. (2019). Would I be helped? Cross-national CCTV footage shows that intervention is the norm in public conflicts. American Psychologist, 75(1), 66-75. https://doi.org/10.1037/ amp0000469

Samaritans. (2018). More of us are acting to help prevent suicide. https://www.samaritans.org/news/more-us-are-acting-helpprevent-suicide/

Sydney Trains. (2018). Annual report 2017-2018. https://www. transport.nsw.gov.au/system/files/media/documents/2018/ Sydney\%20Trains\%20Annual\%20Report\%202017-18.pdf

\section{History}

Received October 7, 2020

Revision received March 10, 2021

Accepted March 18, 2021

Published online August 18, 2021

\section{Conflict of Interest}

No potential conflict of interest was reported by the authors.

\section{Funding}

The research is supported by the Australian Research Council (ARC LP160100910). 


\section{ORCID}

Shirley D. Gregor

(iD) https://orcid.org/0000-0002-0686-8674

\section{Shirley Gregor}

Copland Building 24

The Australian National University

Canberra, ACT 2600

Australia

shirley.gregor@anu.edu.au

Nguyen Viet Ngo, MIntMgt, is a research associate at the Research School of Management at the Australian National University, Canberra, Australia, working as a consultant for the Sydney Trains Project. His primary fields of research are management and international business.

Shirley Gregor, PhD, is Emeritus Professor at the Australian National University, Canberra, Australia. Her primary field of research is information systems and she had led large projects and published in areas including artificial intelligence, human-computer interaction, and the adoption and use of transformative information technologies.

Gary Beavan is the Director Security for Sydney Trains and has held senior leadership roles in the rail industry, intelligence, and law enforcement. He has led programs that improved customer journey times and the security of public transport. Gary Beavan has partnered the rail industry, health professionals, and academics to champion awareness and understanding of suicide.

Bianca Riley, MBA, is an outcomes-focused professional with over 12 years of experience in the rail industry. She has a problem-solving mindset and is not afraid to challenge the norm in her drive for continuous improvement. Bianca Riley also brings first-hand experience in suicide prevention in the rail environment. 